\title{
A statistical study of ion frictional heating observed by EISCAT
}

\author{
J. A. Davies ${ }^{1}$, M. Lester ${ }^{1}$ and I. W. McCrea ${ }^{2}$ \\ ${ }^{1}$ Radio and Space Plasma Physics Group, Department of Physics and Astronomy, University of Leicester, University Road, \\ Leicester, LE1 7RH, UK \\ 2 EISCAT Group, Rutherford Appleton Laboratory, Chilton, Didcot, Oxfordshire, OX11 0QX, UK
}

Received: 20 January 1997 / Revised: 20 May 1997 / Accepted: 22 May 1997

\begin{abstract}
Results of a statistical survey of F-region ion frictional heating are presented, a survey which is based on over $4000 \mathrm{~h}$ of common programme observations taken by the European incoherent scatter (EISCAT) UHF radar facility. The criterion adopted in this study for the identification of ion frictional heating was that defined by McCrea et al., requiring an enhancement in the F-region field-parallel ion temperature exceeding $100 \mathrm{~K}$ over two consecutive integration periods, which was itself based on a selection criterion for frictional heating derived for the study of high-latitude F-region ion temperature observations from the Atmospheric Explorer-C satellite. In the present study, the diurnal distribution of ion frictional heating observed by EISCAT is established and, furthermore, its dependence on geomagnetic activity and the orientation of the interplanetary magnetic field (IMF) is investigated; results are interpreted with reference to corresponding distributions of enhanced ion velocity, again derived from the extended set of EISCAT UHF common programme observations. The radar, due to its location relative to the large-scale convection pattern, observes ion frictional heating principally during the night, although preferentially during the post-midnight hours where there is reduced coupling between the ion and neutral populations. There is an increased preponderance of frictional heating during intervals of high geomagnetic activity and for a southward z component of the IMF and, moreover, evidence of asymmetries introduced by the y component of the IMF.
\end{abstract}

\section{Introduction}

A relative velocity between the ion and neutral populations in the F-region ionosphere results in an enhance-

Correspondence to: J. A. Davies ment in the temperature of the ions through frictional contact with the neutral atmosphere. This mechanism is termed ion frictional heating and, at auroral latitudes where its occurrence was first indicated by satellite observations, is a manifestation of the coupling between the ionosphere and magnetosphere. Frictional heating is one of the principal mechanisms whereby energy originating in the solar wind is deposited into the Earth's ionosphere and ultimately the neutral atmosphere. Ion frictional heating has been extensively described in the literature, by such authors as Rees and Walker (1968), Schunk et al. (1975) and Schunk and Sojka (1982). The neutrals are coupled to the ions by collisions which tend to equalise the velocities of the two populations, a mechanism referred to as ion drag (e.g. Rishbeth, 1972). The response time of the neutral atmosphere to variations in the ion velocity is a function of electron density, and as such is highly variable (Baron and Wand, 1983).

Theory predicts that a relative velocity between the ions and neutrals in the F-region should result in the distortion of the ion thermal velocity distribution from an isotropic Maxwellian, tending towards a torus in velocity space although remaining gyrotropic with respect to the magnetic field. A review of the theory of non-Maxwellian ion velocity distributions and the consequent development of anisotropic ion temperatures is presented by St-Maurice and Schunk (1979). The first experimental evidence indicating the existence of non-Maxwellian line-of-sight ion velocity distributions was provided by the Atmospheric Explorer-C satellite (St-Maurice et al., 1976) and their occurrence has subsequently been identified from radar observations by the European incoherent scatter (EISCAT) radar (Lockwood et al., 1987; Moorcroft and Schlegel, 1988). Anisotropic ion temperatures have been observed, again using EISCAT, by Perraut et al. (1984) and Løvhaug and Flå (1986), amongst others.

In this paper, the results of a statistical study of ion frictional heating are presented, a study which is based on over $4000 \mathrm{~h}$ of observations by the EISCAT UHF 
radar (e.g. Rishbeth and Williams, 1985) taken between October 1984 and December 1995. The UHF common programme modes which provide the measurements for the survey, or more specifically the geometrical arrangements and pulse coding techniques employed, are summarised in Sec. 2. Sections 3 and 4 discuss the criterion adopted for the identification of ion frictional heating and the statistical results, respectively. Subsequently, principal conclusions are reiterated.

\section{Experimental arrangement}

The following investigation is based on F-region observations taken by the EISCAT UHF radar in versions $\mathrm{F}, \mathrm{H}, \mathrm{I}$ and $\mathrm{J}$ of the common programme 1 (CP-1) mode of operation and versions $\mathrm{C}, \mathrm{D}$ and $\mathrm{E}$ of common programme 2 (CP-2). The basic geometry of each common programme is retained through each version to enable long term studies of the type documented in this paper to be performed, although subsequent versions of each programme are updated and refined. The geometrical arrangement of both experiments is discussed and any relevant difference between successive versions of each programme is highlighted.

In the EISCAT CP-1 mode, the beam from the UHF transmitter is aligned along the local magnetic field direction in the F-region which, for a radar located at Troms $\varnothing$, is at an elevation of around $77^{\circ}$ and an azimuth of $182^{\circ}$. In all versions of CP-1 employed in the present study, the remote site radars, at Kiruna and Sodankylä, alternated between E- and F-region observation with a scan of $10 \mathrm{~min}$ duration. In version $\mathrm{F}$ of the $\mathrm{CP}-1$ programme (CP-1-F), the remote site radars performed a five position scan intersecting the transmitter beam at four E-region altitudes and at $312 \mathrm{~km}$ in the F-region. In the subsequent version, $\mathrm{CP}-1-\mathrm{H}$, the remote site scan was slightly modified in that the F-region intersection volume was reduced in altitude to $278 \mathrm{~km}$. In both the CP-1-F and CP-1-H experimental modes, the effective dwell time at the F-region intersection altitude was some 90 s. In CP-1-I and CP-1-J, however, the remote site radars performed an eight position scan intersecting the transmitter beam at six different E-region altitudes and at $278 \mathrm{~km}$ altitude in the F-region, the latter being repeated twice within each scan with a dwell time of approximately $60 \mathrm{~s}$.

In CP-2, the transmitter performs a four position scan, one position of which is vertical and another, fieldaligned. In the remaining two positions, the transmitter points geomagnetically eastward of the zenith. The dwell time for each position of the scan is $1.5 \mathrm{~min}$, giving a total cycle time of $6 \mathrm{~min}$. The remote site radars follow the transmitter beam scan, observing at a fixed F-region altitude, centred around $312 \mathrm{~km}$ for CP-2-C and $278 \mathrm{~km}$ in the subsequent versions, CP-2-D and CP-2-E.

In all versions of both experiments, a long-pulse scheme was transmitted for low-altitude resolution F-region measurements, in addition to either multi- pulse or alternating code transmission for high resolution observations at E-region altitudes. The long-pulse measurements, which are the basis of the present study, yield an altitude resolution of some $22 \mathrm{~km}$ along the magnetic field direction, from approximately 150 to $600 \mathrm{~km}$ altitude, although the actual signal gates overlap to some extent.

For the present study, CP-1 observations from Tromsø were post-integrated at a temporal resolution of $5 \mathrm{~min}$ and the remote site data over the dwell time at each scan position. CP-2 observations from all sites were post-integrated over the dwell time at each scan position.

It is accepted that the analysis of incoherent scatter spectra to provide estimates of ion temperature is limited by three factors when the ion-neutral relative velocity is high; it is, indeed, this parameter under these conditions which provides the basis of the present study. These factors are the occurrence of non-Maxwellian line-of-sight ion thermal velocity distributions, modification of the ion composition and the divergence of the temperatures of the different ion species. The effect of these limitations is briefly discussed with respect to the present observations at salient points in the text, although a more detailed discussion see, for example, McCrea et al. (1995) and references therein.

\section{Selection criterion for the identification of ion frictional heating}

The current study extends that documented by McCrea (1989) and McCrea et al. (1991) in which the authors present the diurnal distribution of ion frictional heating, along with that of the related phenomena of enhanced ion velocity, derived statistically from F-region EISCAT CP-1 and CP-2 observations taken during 1985 and 1986. The criterion employed in the present study for the identification of ion frictional heating is that adopted by McCrea et al. (1991), itself based on a condition derived by St-Maurice and Hanson (1982) for the examination of high-latitude field-perpendicular ion temperature measurements taken by the retarding potential analyser on board the Atmosphere Explorer-C satellite. The selection criterion of St-Maurice and Hanson (1982) for the identification of ion frictional heating required an enhancement in the field-perpendicular ion temperature of at least $200 \mathrm{~K}$ over the values measured in the absence of strong electric fields. The authors concluded that this threshold would exclude enhancements in ion temperature arising from other physical processes, such as heat conduction and thermal energy transfer from the electron population, as well as significantly exceeding the uncertainty in their measurements. St-Maurice and Hanson (1982) quoted a relative ion-neutral drift of between 400 and $600 \mathrm{~m} \mathrm{~s}^{-1}$ as necessary to produce such an enhancement in the field-perpendicular ion temperature.

Under conditions of a large relative velocity between the ion and neutral populations, the 3-dimensional ion 
thermal velocity distribution will become distorted from an isotropic Maxwellian, a phenomenon reviewed by St-Maurice and Schunk (1979). In EISCAT common programme analysis the ion temperature is derived by assuming that the ion velocity distribution along the direction of observation is Maxwellian; an assumption which has been demonstrated theoretically to lead to an overestimate in the ion temperature in situations where the velocity distribution is non-Maxwellian (e.g. Lockwood et al., 1993). Theoretical predictions, however, indicate that along the field-parallel direction the departure of the ion velocity distribution from a Maxwellian is small and that the line-of-sight ion temperature derived by assuming a Maxwellian velocity distribution is accurate to within $5 \%$ for field-perpendicular ion velocities of up to some $4 \mathrm{~km} \mathrm{~s}^{-1}$ (Lathuillère and Hubert, 1989). For this reason, McCrea et al. (1991) constrained their analysis to that of EISCAT observations taken along the magnetic field direction, i.e. from $\mathrm{CP}-1$ and the field-aligned position of CP-2. Since the satellite observations for which St-Maurice and Hanson (1982) derived their threshold for the identification of ion frictional heating were restricted to a direction orthogonal to the geomagnetic field, McCrea et al. (1991) suggested that the threshold should be adapted for studies based on measurements taken along the magnetic field direction. The latter authors stated that in the ionospheric F-region, for $\mathrm{O}^{+}-\mathrm{O}$ interactions constituting the dominant collision mechanism, a field-perpendicular ion temperature enhancement of $200 \mathrm{~K}$ would be accompanied by an enhancement in the fieldparallel ion temperature of only around $100 \mathrm{~K}$, due to the unequal partition of energy into the field-parallel and field-perpendicular ion populations. McCrea et al. (1991) thus adopted $100 \mathrm{~K}$ as the enhancement in the field-parallel ion temperature necessary for the identification of ion frictional heating.

Under conditions of a large ion-neutral relative velocity, the proportion of molecular ions in the F-region, particularly $\mathrm{NO}^{+}$, increases as a consequence of enhancements in both the reaction rate coefficients and the concentration of reactant neutrals (e.g. StMaurice and Torr, 1978). The modification of the ion composition due to the existence of differential flow between the ion and neutral populations can result in substantial underestimation of the ion temperature derived from standard analysis of incoherent scatter data. Moreover, under such conditions the field-parallel ion temperature components for the atomic and molecular ion species can diverge significantly; in the parallel direction the temperature of $\mathrm{NO}^{+}$has been predicted theoretically to exceed that of $\mathrm{O}^{+}$by almost $500 \mathrm{~K}$ for an ion velocity around $1 \mathrm{~km} \mathrm{~s}^{-1}$ and a neutral atmosphere dominated by atomic oxygen (Lathuillère and Hubert, 1989). Standard analysis of EISCAT data assumes, however, that the ion population can be described by a single ion temperature, which, for a multi-ion plasma, is a non-linear combination of the temperatures of the individual ion species present. McCrea et al. (1991) concentrated on observations from the range gate centred at the altitude of $312 \mathrm{~km}$ to perform their study, which corresponded to the F-region tristatic altitude for the CP-1 and CP-2 observations employed. At this altitude, the authors stated that it would be unlikely that significant proportions of molecular ions would be produced for the majority of intervals of ion frictional heating.

Furthermore, McCrea et al. (1991) imposed the criterion that the field-parallel ion temperature must be enhanced by more than $100 \mathrm{~K}$ for two or more consecutive integration periods to exclude anomalous spikes in the ion temperature data. The authors noted that such spikes, which did not correlate with enhancements in the ion velocity, were a regular feature of the ion temperature data and considered them unlikely to be associated with actual physical structures but speculated that they arose from contamination of the radar data due to the presence of a satellite in the side lobes of the radar beam or due to a system fault. It has, however, been observed that the electric field in the auroral F-region can fluctuate over time scales of the order of a few seconds (e.g. Williams et al., 1990; Lanchester et al., 1996) and the inclusion of this condition unfortunately had the effect of eliminating some ion temperature enhancements which corresponded to instances of ion frictional heating occurring on time scales shorter than a single $5 \mathrm{~min}$ integration period.

Implementation of the selection criterion for the identification of intervals of ion frictional heating relies on the calculation of an ambient value of ion temperature, defined as that in the absence of a relative velocity between the ion and neutral populations. St-Maurice and Hanson (1982), for their study of ion data from the Atmospheric Explorer-C satellite, chose as their baseline temperature the ion temperature from nearby positions of the orbit where no, or very weak, electric fields were found. McCrea et al. (1991) suggested that the modal value would be an appropriate estimate of the equilibrium ion temperature; as the ion temperature at a given altitude exhibits little diurnal variation the mode would remain a valid description of the ambient ion temperature regardless of time of day. The authors calculated the ambient ion temperature, for each run of EISCAT observations, as the central temperature of the modal bin of the ion temperature distribution, calculated with a bin size of $10 \mathrm{~K}$.

To assist in their interpretation of the distribution of ion frictional heating, McCrea (1989) also deduced the distribution with universal time of the occurrence of enhanced ion velocities from their two year set of UHF EISCAT common programme observations. The author applied the criterion that the magnitude of the ion velocity, calculated at the F-region tristatic altitude, should exceed $500 \mathrm{~m} \mathrm{~s}^{-1}$; this threshold was selected as it is approximately the ion velocity required to produce an enhancement in the F-region field-parallel ion temperature of $100 \mathrm{~K}$, although this assumes a stationary neutral atmosphere. In order to eliminate unreliable estimates of ion velocity, any velocity estimates for which the signal-to-noise ratio at any of the three UHF receiver sites was less than $2 \%$ were excluded. 


\section{Statistical study of ion frictional heating: results}

\subsection{Diurnal distribution of ion frictional heating}

The selection criterion described in the previous section for the identification of ion frictional heating was applied to the present extended data set of CP-1 and field-aligned CP-2 observations of field-parallel ion temperature at $312 \mathrm{~km}$ altitude. Satisfaction of the criterion requires, in summary, an enhancement in the field-parallel ion temperature, over the modal value derived for that run, equal to or exceeding $100 \mathrm{~K}$, for a minimum of two consecutive integration periods; temperatures are those measured by EISCAT in the range gate centred at $312 \mathrm{~km}$ altitude. A total of 1152 intervals of frictional heating were identified from the $4230 \mathrm{~h}$ set of field-parallel ion temperature observations, ranging in duration from the minimum of 2 integration periods, 10 and $12 \mathrm{~min}$ for CP-1 and CP-2, respectively, to several hours. Ion frictional heating was observed to some extent during the vast majority of the EISCAT common programme runs incorporated in the present study.

As in the study of McCrea et al. (1991), the diurnal distribution of ion frictional heating was constructed by dividing the day into $30 \mathrm{~min}$ bins and summing the number of occasions over the entire data set on which heating occurs in each bin. Intervals of frictional heating which span 30 min boundaries contribute in each time bin in which they were observed. The observational coverage, however, is not uniform throughout the day, with a minimum in the number of radar observations between 22:00 UT and 08:00 UT; the number of observations of each $30 \mathrm{~min}$ bin lies between some 150 and 200. To negate the effect of non-uniform sampling the diurnal distribution of ion frictional heating was derived as a percentage of the number of observations of each half-hour bin. The diurnal distribution of ion frictional heating derived from EISCAT UHF fieldparallel CP-1 and CP-2 measurements at $312 \mathrm{~km}$ altitude is presented as a function of universal time in Fig. 1. The histogram represents the percentage occurrence of ion frictional heating as a function of universal time, with a bin width of 30 min extent (left-hand-scale); the line plot illustrates the number of observations of each bin (right-hand-scale).

The diurnal distribution of F-region ion frictional heating observed by EISCAT at $312 \mathrm{~km}$ altitude exhibits a broad peak in the night-time sector, with relatively little heating occurring between 06:00 and 13:00 UT on the dayside. The distribution is centred at approximately 20:00 UT about which it is asymmetric, with a propensity for ion frictional heating in the early morning sector, some $50 \%$ maximum occurrence, and a somewhat smaller peak in occurrence, approximately $35 \%$, around 17:00 UT. Between 18:00 and 21:00 UT on the nightside there is a slight reduction in the occurrence of ion frictional heating; the probability of observing frictional heating in any half-hour bin during this interval is around $30 \%$. A physical interpretation of the diurnal variation in the occurrence of F-region ion frictional heating observed by EISCAT is detailed later

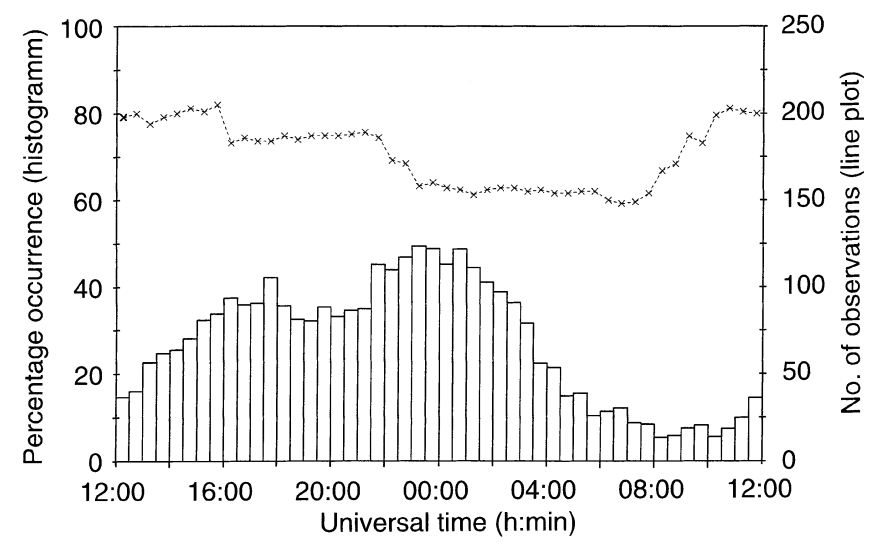

Fig. 1. Diurnal distribution of ion frictional heating at $312 \mathrm{~km}$ altitude, derived from over $4000 \mathrm{~h}$ of field-parallel EISCAT UHF common programme observations taken between 1984 and 1995. The histogram represents the percentage occurrence of ion frictional heating as a function of universal time, with a bin width of $30 \mathrm{~min}$; the line plot indicates the number of observations of each half-hour bin

in the present section, particularly with reference to the observed distribution of enhanced ion flow.

The variation of the enhancement in the field-parallel ion temperature at $312 \mathrm{~km}$ altitude, during identified intervals of ion frictional heating, is illustrated as a function of universal time in Fig. 2. The solid line represents the median value of the field-parallel ion temperature enhancement in each half-hour bin, for all integration periods during recognised intervals of frictional heating (left-hand-scale); the vertical lines encompass the range of parallel temperature enhancements bounded by the upper and lower quartiles. The number of estimates of the field-parallel ion temperature enhancement in each $30 \mathrm{~min}$ bin is signified by the dotted line (right-hand-scale). The criterion for the identification of ion frictional heating that the enhancement in the parallel ion temperature should exceed $100 \mathrm{~K}$, imposes that threshold as a lower limit on the median enhance-

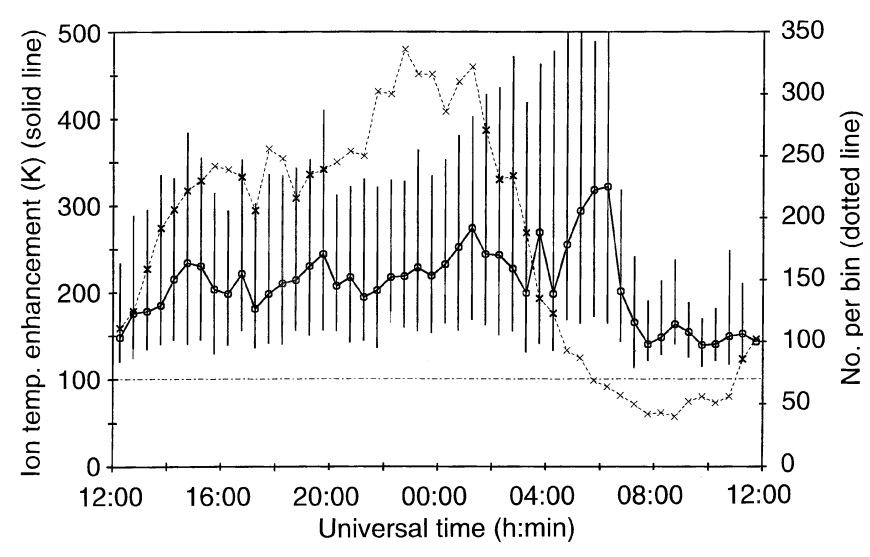

Fig. 2. Enhancement in the field-parallel ion temperature during identified intervals of ion frictional heating, plotted as a function of universal time. The solid line indicates the median temperature enhancement in each $30 \mathrm{~min}$ bin, with vertical lines which encompass the range bounded by the upper and lower quartiles. The dotted line illustrates the number of estimates of the enhancement in each bin 
ment observed. The median field-parallel temperature enhancement during recognised intervals of ion frictional heating exhibits a distinct dependence with universal time, ranging from a maximum approaching $350 \mathrm{~K}$ around 06:00 UT to little over 100 K between 07:00 and 13:00 UT on the dayside. Furthermore, the spread of observed parallel ion temperature enhancements tends to be far greater after 13:00 UT and prior to 07:00 UT on the nightside; near 06:00 UT, for example, a quarter exceed some $500 \mathrm{~K}$. Although the median enhancement in the field-parallel ion temperature tends to be greater over those range of universal times where the probability of occurrence of ion frictional heating is high, the maximum ion temperature enhancement, observed around 06:00 UT, corresponds to a time of low occurrence of ion frictional heating.

The duration of each interval of ion frictional heating, identified from the extended data set of common programme observations, was also noted. Figure 3 presents the diurnal variation of the duration of ion frictional heating, identified by the selection criterion discussed in the previous section. The format of this illustration is similar to that of the previous figure. The solid line (corresponding to the left-hand-scale) represents the median value of the duration of identified intervals of ion frictional heating in each half-hour bin; the vertical lines span the range of durations bounded the upper and lower quartiles. The dotted line (righthand-scale) corresponds to the number of estimates of the duration of frictional heating in each $30 \mathrm{~min}$ bin. The duration of intervals of ion frictional heating which span 30 min boundaries contribute in each bin in which the event was observed. The minimum duration of intervals of frictional heating is set by the selection criterion, two integration periods corresponding to $10 \mathrm{~min}$ and $12 \mathrm{~min}$ for $\mathrm{CP}-1$ and $\mathrm{CP}-2$, respectively.

The duration of identified intervals of ion frictional heating exhibits an obvious diurnal variation; frictional heating events characterised by a long duration tend to occur on the nightside. The median duration of identi-

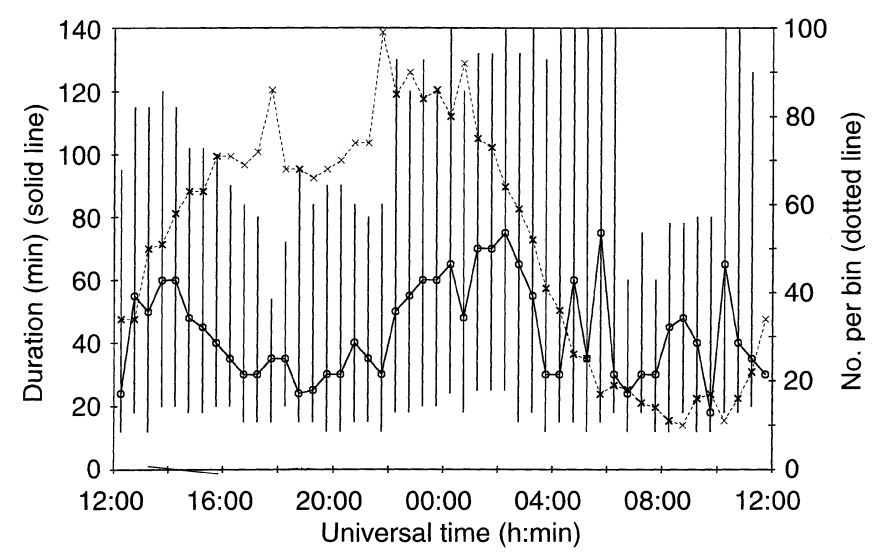

Fig. 3. Duration of identified intervals of ion frictional heating, as a function of universal time. The solid line represents the median duration, in each half-hour bin, with vertical lines which span the range of durations bounded by the upper and lower quartiles. The dotted line indicates the number of estimates of duration in each bin fied intervals of ion frictional heating exceeds $60 \mathrm{~min}$ between 00:00 and 02:00 UT, reducing to between 20 and 30 min between 06:00 and 12:00 UT on the dayside. Frictional heating of prolonged duration corresponds, in general, to periods where the probability of observing such heating is higher, and those which are observed are characterised by larger temperature enhancements. Between 16:00 and 22:00 UT a distinct reduction in event duration is noted; between these hours the duration of frictional heating events reduces to similar values to those observed in the dayside hours. The minimum in the duration of frictional heating between 16:00 and 22:00 UT on the nightside is rather more marked than the corresponding minimum in the percentage occurrence of frictional heating.

The observed absence of ion frictional heating, by EISCAT, on the dayside is a consequence of the equatorward edge of the ionospheric convection pattern typically being situated far poleward of the radar during these hours, a result of the displacement of the convection pattern as a whole in the antisunward direction. More interesting, however, is the observed asymmetry between the occurrence of ion frictional heating prior to magnetic midnight and that in the post-midnight sector. These observations are consistent with those of Baron and Wand (1983), Alcaydé et al. (1984), Alcaydé and Fontanari (1986) and Moorcroft and Schlegel (1988) in that these authors also reported a propensity for the occurrence of ion frictional heating during the hours post magnetic midnight. The dawn-dusk asymmetry in the occurrence of ion frictional heating results from the tendency for smaller neutral winds to develop during the post-midnight sector than prior to magnetic midnight, an effect to which several processes are thought to contribute.

The F-region electron density is generally lower in the morning sector than during the afternoon and evening hours, due to the decay of solar-produced ionisation, thus the ion drag force on the neutral atmosphere, which is proportional to the plasma concentration, will tend to be less (Baron and Wand, 1983). This weaker coupling between the ions and the neutral population postmidnight, results in larger ion-neutral relative velocities and, in consequence, more intense ion frictional heating during these hours. Another factor which determines the extent to which the neutral wind can be accelerated by ion drag is the length of time for which it is resident in the region of large auroral ion flows. In the dusk sector, the Coriolis and centrifugal accelerations of a packet of neutral air tend to cancel and its motion is largely westward; air which remains within the region of strong auroral ion flows acquires a large westward velocity. Conversely, in the dawn convection cell both centrifugal and Coriolis forces act in the same direction, moving the packet of neutral air equatorward out of the oval thus preventing it from acquiring a large momentum from the ions (e.g. Lockwood and Fuller-Rowell, 1987a, b). Both of these factors account for the observations of Baron and Wand (1983) and Moorcroft and Schlegel (1988), amongst others, of larger ion temperatures in the postmidnight sector. Alcaydé et al. (1984) proposed an 
additional mechanism which would contribute to this effect; a mechanism also relating to the role of the Coriolis force on the neutral atmosphere. The authors pointed out that the strongly developed southward neutral winds which exist on the nightside under both disturbed and quiet conditions, a feature of global thermospheric circulation, would induce a Coriolis force which opposes the ion drag force arising from eastward plasma flow during the post-midnight hours whereas in the evening sector these two forces would act in the same direction.

To aid the interpretation of the diurnal distribution of ion frictional heating it is instructive to construct a similar distribution with universal time of enhanced ion velocity. The selection criterion adopted was that suggested by McCrea (1989) for the identification of intervals of enhanced ion flow; the magnitude of the ion velocity should exceed $500 \mathrm{~m} \mathrm{~s}^{-1}$, the velocity necessary to produce an enhancement of $100 \mathrm{~K}$ in the ion temperature component parallel to the geomagnetic field. To exclude unreliable estimates of velocity, the condition was implemented that the signal-to-noise ratio at each receiver site should exceed $2 \%$; a threshold suggested by McCrea (1989). Figure 4 presents the diurnal distribution of ion velocities exceeding $500 \mathrm{~m} \mathrm{~s}^{-1}$, derived from the extended set of common programme 1 and 2 observations. As for Fig. 1, the histogram expresses, effectively, the probability of observing enhanced ion velocities in any $30 \mathrm{~min}$ bin during the day (left-hand-scale) and the line plot indicates the number of observations of each bin (right-hand-side). Moreover, velocities have been subdivided according to the orientation of the zonal flow; ion velocities in which the zonal component is westward are represented as light shading whereas darker shading illustrates ion velocities with an associated eastward component. The number of observations of each $30 \mathrm{~min}$ bin in Fig. 4 tends to be less than that in Fig. 1, the former ranging from some 120 to 180 and the latter from 150 to 200 ; it is

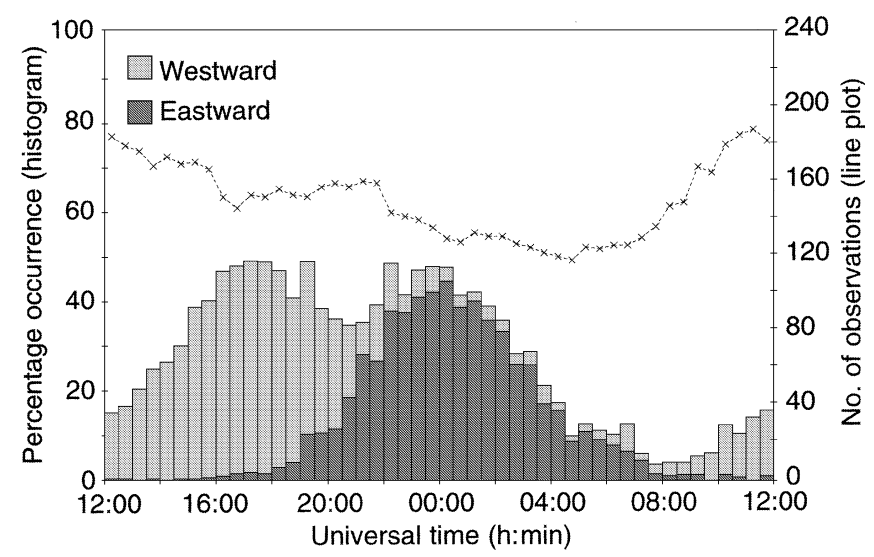

Fig. 4. Diurnal distribution of F-region ion velocities exceeding $500 \mathrm{~m} \mathrm{~s}^{-1}$, observed by EISCAT. The histogram represents the percentage occurrence of enhanced ion velocity as a function of universal time, the bin width again $30 \mathrm{~min}$; light grey shading indicates enhanced ion velocities with a westward zonal component, dark grey indicates those with an eastward zonal component. The line plot shows the number of observations of each half-hour bin necessary to have line-of-sight ion velocity measurements from all UHF receiver sites in order to estimate the magnitude of the ion velocity and the returns from which these velocities are obtained are, moreover, subject to a $2 \%$ signal-to-noise threshold.

An exact correspondence between the ion velocity magnitude and the enhancement in the parallel ion temperature, and consequently their diurnal distributions, is not expected since it is the relative ion-neutral velocity that determines the extent of frictional heating of the ion population and not simply the magnitude of the ion velocity. The distribution of enhanced ion velocities exhibits a similar form to that of ion frictional heating, a broad peak about midnight with a central minimum corresponding to the location of the nightside convection reversal which is characterised by lower velocities. Ion velocities exceeding $500 \mathrm{~m} \mathrm{~s}^{-1}$ are seldom observed by EISCAT between 06:00 and 12:00 UT due to the antisunward displacement of the convection pattern. The nightside convection reversal, corresponding to a change from eastwards to westward flow, is generally located temporally between 18:00 and 22:00 UT at the latitude of EISCAT. The occurrence of enhanced ion velocities appears symmetric about the nightside reversal, implying the equal occurrence of enhanced ion velocities in the dawn (westward) and dusk (eastward) convection cells, although the tendency for lower neutral atmosphere response times and the opposition of the ion drag and Coriolis forces during the early morning hours gives rise to asymmetry in the distribution of ion frictional heating between these two regimes. Within the convection reversal, intervals of ion frictional heating are characteristically of very short duration, comparable to that of intervals observed by EISCAT on the dayside. This highlights the highly dynamic nature of this region of plasma flow.

The asymmetric response of the F-region ion temperature to enhancements in the dawn and dusk convection cells can be investigated more fully using simultaneous observations of the ion vector velocity determined at the tristatic altitude and the enhancement in the field-parallel ion temperature during intervals of ion frictional heating. Figure 5 presents the variation in the median enhancement in the field-parallel ion temperature at $312 \mathrm{~km}$ altitude during identified intervals of ion frictional heating as a function of the simultaneously observed ion velocity magnitude, derived from the set of EISCAT CP-1 and CP-2 observations. The ion velocity observations have, moreover, been classified according to the orientation of their field-orthogonal zonal component. The left-hand-side of Fig. 5 illustrates the variation of field-parallel temperature enhancement with ion velocity magnitude where the field-perpendicular zonal component of the ion velocity is westward; the right-hand-side of the figure shows the functional response of the ion temperature enhancement with velocity magnitude where the associated zonal velocity component is eastward. The ion temperature enhancement has been binned according to ion velocity with a bin width in velocity of $100 \mathrm{~m} \mathrm{~s}^{-1}$. For both orientations of the zonal velocity component, vertical bars join the 


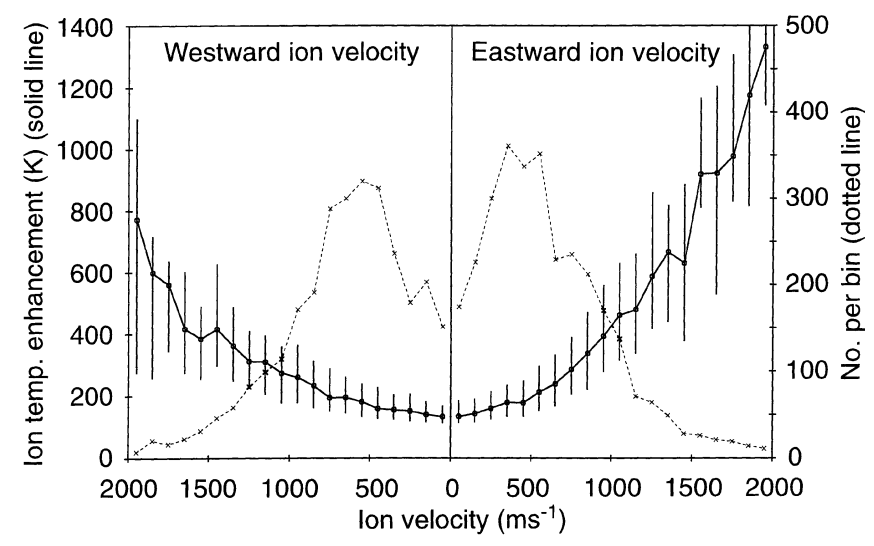

Fig. 5. Field-parallel ion temperature enhancement as a function of ion velocity during identified intervals of ion frictional heating, subdivided according to the orientation of the field-orthogonal zonal component of the ion velocity. The solid line shows the median enhancement in each $100 \mathrm{~m} \mathrm{~s}^{-1}$ width velocity bin, with vertical lines which indicate the range bounded by the upper and lower quartiles. The dotted line represents the number of estimates of parallel temperature enhancement in each velocity bin

upper and lower quartiles of the temperature enhancement in each velocity bin, and the dotted line indicates the number of estimates of the parallel ion temperature enhancement in each velocity bin.

The response of the field-parallel ion temperature with ion velocity magnitude is clearly asymmetric with respect to the zonal velocity component; in the dusk convection cell an ion velocity of $1000 \mathrm{~m} \mathrm{~s}^{-1}$ results in a median enhancement of around $250 \mathrm{~K}$ in the parallel ion temperature whereas an equivalent velocity in the dawn cell enhances the ion temperature by more than $400 \mathrm{~K}$. For an ion velocity of $1500 \mathrm{~m} \mathrm{~s}^{-1}$, the corresponding temperature enhancements are approximately 350 and $600 \mathrm{~K}$ in the dusk and dawn cells of the convection pattern, respectively. The results presented are not directly comparable to those of Baron and Wand (1983); the latter authors presented observations of ion temperature as a function of the zonal ion velocity from both the Chatanika and Millstone Hill incoherent scatter radars during two limited intervals. Although the work of Baron and Wand (1983) indicates a larger enhancement in ion temperature for a given ion velocity for both orientations of zonal flow, this is accounted for by the larger aspect angle of their observations, indeed the Chatanika beam was zonally directed.

\subsection{Variation with interplanetary magnetic field orientation}

The solar wind plasma and the interplanetary magnetic field (IMF) have been consistently monitored since 1963, by a series of spacecraft such as IMP-1 to 8, HEOS and ISEE-1 to 3. Hourly averages of the interplanetary magnetic field components, in addition to solar wind velocity and dynamic pressure measurements, are available during the intervals when the satellites were upstream of the bow shock. The IMF measurements covering the period of the present set of EISCAT observations were taken by the IMP-8 spacecraft. Although the proportion of each individual spacecraft orbit for which observations are available is highly variable, approximately half of the EISCAT data set employed in the current statistical study has associated IMF coverage. The response time of the ionosphere to variations in the interplanetary magnetic field ranges between some tens of minutes on the dayside to more than an hour on the nightside (Todd et al., 1988; Lester et al., 1993). It is, therefore, inappropriate to use observations of the interplanetary magnetic field at any higher time resolution than hourly averages in the present study, although IMF and solar wind data are available at up to $30 \mathrm{~s}$ resolution.

The present EISCAT field-parallel ion temperature and ion velocity observations have been classified according to the orientation of both the northward $\left(B_{\mathrm{z}}\right)$ and eastward $\left(B_{\mathrm{y}}\right)$ components of the IMF where these components are measured in the GSM (geocentric solar magnetic) coordinate system. Initial classification was according to the $B_{\mathrm{z}}$ component of the IMF. The upper two panels of Fig. 6 illustrate the diurnal distribution of ion frictional heating observed by EISCAT for $B_{\mathrm{z}}$ negative (southward) and $B_{\mathrm{z}}$ positive (northward), irrespective of the orientation of the y component of the interplanetary magnetic field. As in previous figures of this type, the histograms represent the percentage occurrence of ion frictional heating and the line plots, the total number of observations, in each $30 \mathrm{~min}$ bin for each orientation of $B_{\mathrm{z}}$.

For both orientations of $B_{\mathrm{z}}$, the diurnal distribution of ion frictional heating exhibits a similar general form to that illustrated in Fig. 1, that is a broad and asymmetric distribution, centred in the midnight sector. At all universal times, however, the probability of observing ion frictional heating in a half-hour bin is far greater for a southward orientation of $B_{\mathrm{z}}$ than for a northward $B_{\mathrm{z}}$; between 00:00 and 02:00 UT the percentage occurrence of frictional heating for $B_{\mathrm{z}}$ negative approaches $60 \%$ whereas for positive values of $B_{\mathrm{z}}$, the corresponding figure is less than $30 \%$. The minimum in the occurrence of frictional heating, corresponding to the general location of the night-time convection reversal, appears less clearly defined for the case of southward $B_{\mathrm{z}}$ than it is for northward $B_{\mathrm{z}}$. During conditions of southward $B_{\mathrm{z}}$, both the size and duration of identified intervals of frictional heating (not illustrated) are also significantly greater than those for a northward $\mathrm{z}$ component of the interplanetary magnetic field; on the nightside the median enhancement in the field-parallel ion temperature for southward $B_{\mathrm{z}}$ generally exceeds that for northward $B_{\mathrm{z}}$ by more than $100 \mathrm{~K}$ and the median duration is almost doubled.

The dependence of high-latitude ionospheric convection on the orientation of the interplanetary magnetic field provides an explanation for these observations (e.g. Friis-Christensen et al., 1985). There is little doubt that the interplanetary magnetic field strongly influences magnetospheric and ionospheric convection although the exact processes involved in solar wind/magneto- 

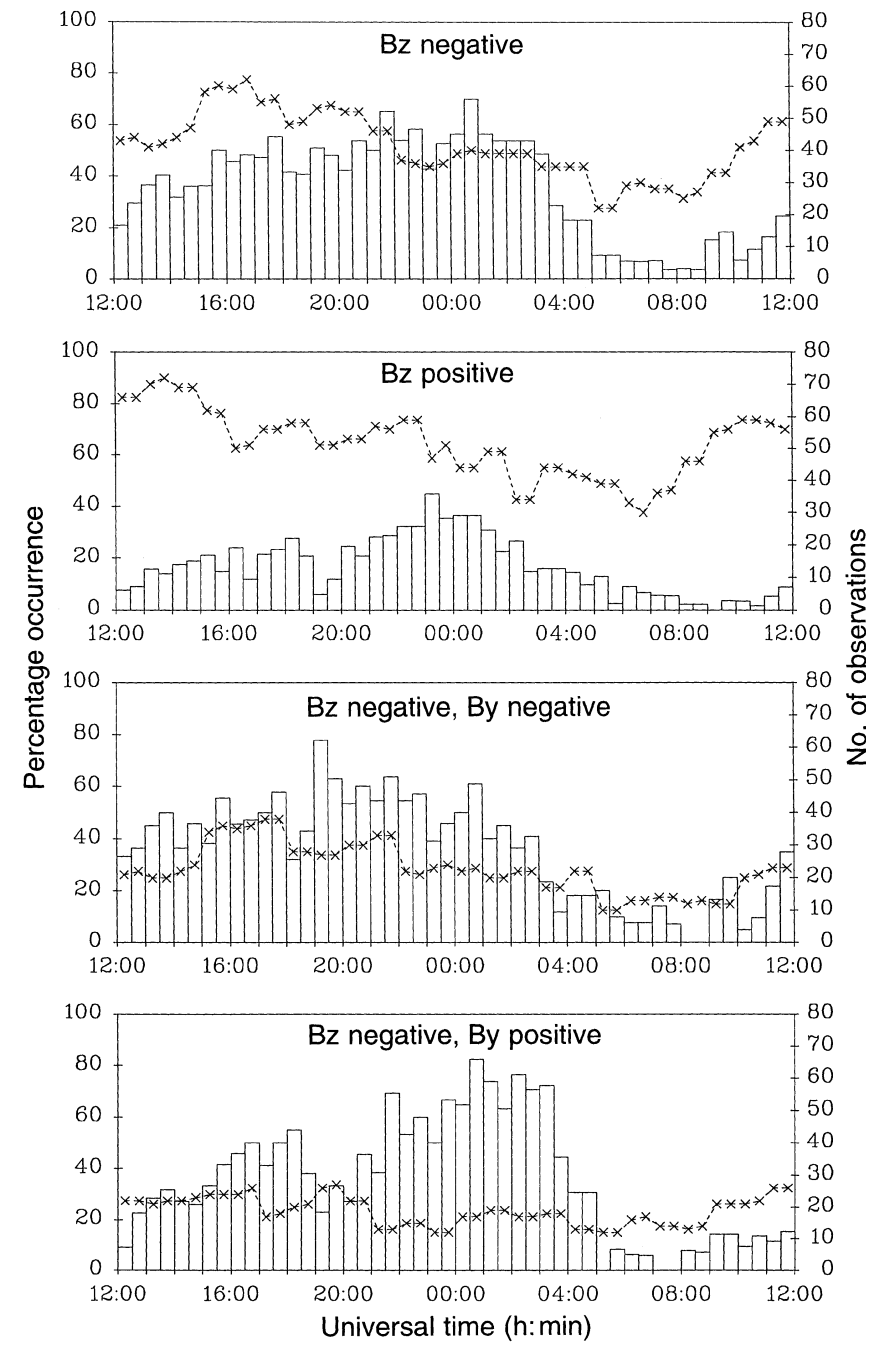

Fig. 6. Variation of the diurnal distribution of ion frictional heating with the orientation of the $\mathrm{y}$ and $\mathrm{z}$ components of the interplanetary magnetic field. The form of each panel is the same as that of Fig. 1

sphere/ionosphere coupling are not well determined. It is generally accepted that convection in the dayside ionosphere is driven by reconnection at the nose of the magnetosphere, the rate of which is highly dependant on the orientation of the $\mathrm{z}$ component of the IMF with a southward $B_{\mathrm{Z}}$ required for reconnection at low magnetic latitudes. The resulting build-up of magnetic flux on the tailside leads to the substorm expansion phase, which drives impulsive convection more confined to the nightside ionosphere. Viscous processes in the magnetosphere are also suggested to drive convection in the ionosphere, irrespective of the orientation of the $\mathrm{z}$ component of the IMF (Axford and Hines, 1961). Previous authors have, therefore, attributed ionospheric flows observed under conditions of northward $B_{\mathrm{z}}$ to viscous interaction. Recent research, however, indicates that enhanced convection on the nightside can persist for many hours after a northward turning of the $\mathrm{z}$ component of the IMF, driven by residual reconnection of open flux in the magnetotail, thus mimicking the effect of viscous interaction (Lockwood and Cowley, 1992;
Fox et al., 1994). This interpretation complements the findings of Wygant et al. (1983) which revealed that the convection electric field reduces over about $9 \mathrm{~h}$ after a northward turning of $B_{\mathrm{z}}$. Overall, the pattern of ionospheric convection is, if anything, more complex under conditions of northward $B_{\mathrm{z}}$ than for southward $B_{\mathrm{z}}$ (e.g. Cowley, 1982).

Foster et al. (1986), as the foundation of an empirical model, constructed statistical patterns of high-latitude ionospheric convection based on ion velocity measurements by the Millstone Hill incoherent scatter radar, classified according to the orientation of the IMF, using hourly averages of the latter. The authors found that the convection pattern greatly enhanced and expanded for negative values of $B_{z}$. Consequently, the occurrence of ion frictional heating would be expected to depend critically on the orientation of the $\mathrm{z}$ component of the IMF, with larger convection velocities, thus a greater percentage of ion frictional heating, expected for southward values of $B_{\mathrm{z}}$.

The diurnal distributions of enhanced ion velocities observed by EISCAT, those exceeding $500 \mathrm{~m} \mathrm{~s}^{-1}$, for both negative and positive $\mathrm{z}$ components of the IMF are illustrated in the upper panels of Fig. 7. As in Fig. 4, the ion velocity is further categorised according to its associated zonal component, to enable the location of the convection reversal to be more clearly determined. It is evident that the far greater proportion of frictional heating observed under conditions of southward $B_{\mathrm{z}}$ than when the $\mathrm{z}$ component of the IMF is oriented northward, is attributable to the higher occurrence of enhanced ion velocities during such intervals. As noted previously, the response time of ionospheric highlatitude convection after a southward turning of the $\mathrm{z}$ component of the IMF is some tens of minutes on the dayside to perhaps $90 \mathrm{~min}$ on the nightside. Moreover, even several hours after the IMF $\mathrm{z}$ component has turned northward, the effect of residual tail reconnection on nightside convection can still be significant (Lockwood and Cowley, 1992). These factors might be suggested to account for the relatively high occurrence of ion frictional heating when simultaneous satellite observations indicate a northward $B_{\mathrm{z}}$, particularly as frictional heating is principally observed by EISCAT on the nightside. However, the immediate past history of the IMF is actually found not to affect significantly the distributions presented in Fig. 6. It is also interesting to note that for southward $B_{\mathrm{z}}$ the ion flow observed at EISCAT (albeit restricted to velocities exceeding $500 \mathrm{~m} \mathrm{~s}^{-1}$ ) is separated into two distinct regimes with respect to its zonal component whereas, under situations of northward $B_{\mathrm{z}}$, the demarcation between eastward and westward zonal ion flow is not clearly defined and, indeed, the majority of enhanced flow has an associated eastward zonal component. This is, perhaps, a manifestation of a more complex convection pattern associated with northward $B_{\mathrm{z}}$ than the simple twin cell pattern which is associated with intervals of southward $B_{\mathrm{z}}$.

Empirical models of ionospheric convection (e.g. Reiff and Burch, 1985; Burch et al., 1985) illustrate a strong skew imposed on the convection pattern by the 

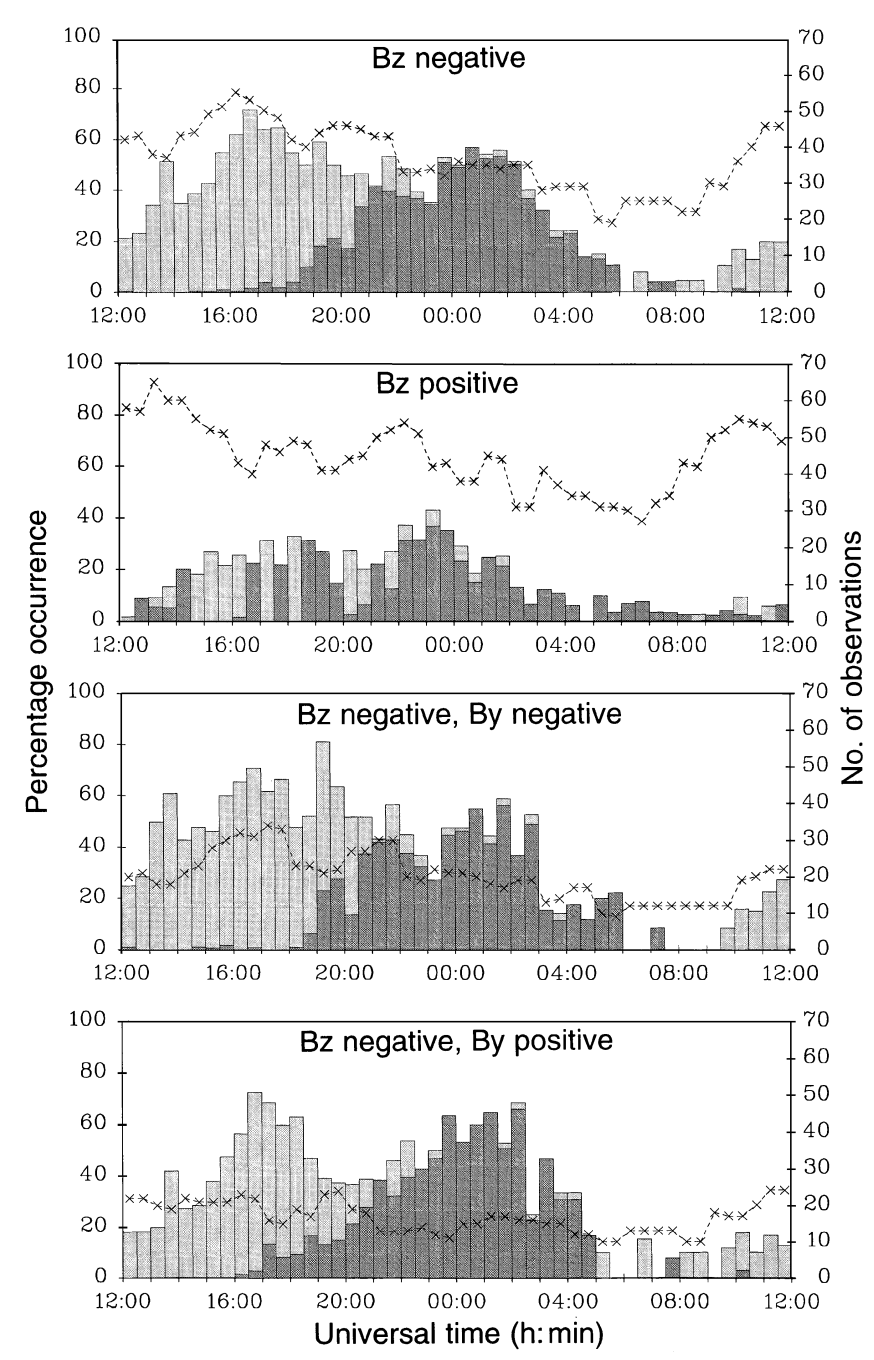

Fig. 7. Variation of the diurnal distribution of enhanced ion velocity with the orientation of the $y$ and $\mathrm{z}$ components of the interplanetary magnetic field. Each panel is presented in the same form as Fig. 4

eastward (y) component of the IMF, reflecting asymmetries in magnetospheric convection dictated by $B_{\mathrm{y}}$, particularly under conditions of southward $B_{\mathrm{z}}$ where convection is excited primarily by reconnection. These models are, however, based mainly on observations around noon. Further observational evidence for a $B_{\mathrm{y}}$ influence on ionospheric convection has been presented by such authors as Rodger et al. (1984), de la Beaujardière et al. (1985, 1986) and Burrage (1988), although the inferred details of the convection patterns vary from those modelled, in particular with the observed patterns for $B_{\mathrm{y}}$ negative not simply being mirror images of the $B_{\mathrm{y}}$ positive patterns.

The diurnal distribution of ion frictional heating has been derived from the EISCAT field-parallel CP-1 and CP-2 observations at $312 \mathrm{~km}$ altitude for positive (eastward) and negative (westward) values of $B_{\mathrm{y}}$, both under conditions of negative $B_{\mathrm{z}}$. The lower two panels of Fig. 6 present the percentage occurrence of ion frictional heating with universal time for $B_{\mathrm{z}}$ negative with $B_{\mathrm{y}}$ negative and $B_{\mathrm{z}}$ negative with $B_{\mathrm{y}}$ positive. As in previous figures, the number of observations of each $30 \mathrm{~min}$ bin are represented by a dotted line. Equivalent distributions of enhanced ion velocity are illustrated in the lower panels of Fig. 7. It is, however, only possible to draw speculative conclusions due to the relatively low number of observations available.

The diurnal distribution of ion frictional heating appears to be very different for the two orientations of the y component of the interplanetary magnetic field, a difference which is clearly attributable to a corresponding difference between the occurrence distributions of enhanced ion velocities. For $B_{\mathrm{y}}$ negative, the maximum occurrence of frictional heating of the F-region ions occurs around 20:00 UT, whereas, for $B_{\mathrm{y}}$ positive, this time corresponds to a minimum in the occurrence of ion frictional heating on the nightside. Moreover, for $B_{\mathrm{y}}$ negative there is a much higher percentage occurrence of ion frictional heating during the interval from 12:00 to 16:00 UT than for $B_{\mathrm{y}}$ positive and somewhat less frictional heating is observed around 00:00 UT. It must be reiterated that both distributions are derived from data taken during periods of negative $B_{\mathrm{z}}$. It is not worthwhile to compare rigorously the distributions of enhanced ion velocity observed by EISCAT, for both orientations of $B_{\mathrm{y}}$, with observed and modelled convection patterns presented by previous authors. There is, however, a feature evident in the present observations that agrees well with statistical convection patterns derived from the SABRE coherent scatter radar measurements, presented by Burrage (1988); this feature is the displacement in local time of the location of the nightside convection reversal between negative and positive values of $B_{\mathrm{y}}$. For $B_{\mathrm{y}}$ negative, the location of the convection reversal, identified from Fig. 7, is situated close to 19:00 UT, with no observations of eastward velocity prior to 18:00 UT whereas, for positive values of $B_{\mathrm{y}}$, the night-time reversal is displaced to an earlier local time by approximately an hour. This displacement is consistent with that observed by Burrage (1988) at the same geomagnetic latitude as the present observations, and supports the conclusions of de la Beaujardière et al. (1985), whose Sondrestromfjord incoherent scatter radar observations indicated that the effect of $B_{\mathrm{y}}$ is not limited to the noon hours. Present results are also consistent with those inferred from magnetometer measurements by Rodger et al. (1984). The results of Rodger et al. (1984) indicate that, in the Northern Hemisphere, the position of the night-time convection reversal is at later local times for negative $B_{\mathrm{y}}$ than for positive $B_{\mathrm{y}}$ whereas, in the southern hemisphere, the converse is true.

\subsection{Variation with geomagnetic activity}

Geomagnetic conditions reflect to some extent the magnitude and orientation of $B_{z}$, such that highly disturbed geomagnetic conditions correspond in general to large southward values of the IMF. More accurately, geomagnetic activity is a gauge of the energy input into the magnetosphere from the solar wind by the interaction of both magnetic fields and particles. Geomagnetic activity may be crudely characterised by $\mathrm{K}_{\mathrm{p}}$ (Bartels, 
1949), a 3 hourly planetary index derived from magnetometer measurements from eleven mid-latitude stations, 10 from the Northern Hemisphere and 1 from the Southern Hemisphere. $\mathrm{K}_{\mathrm{p}}$, a quasi-logarithmic index, is scaled from 0 to 9 with increments $-, 0,+$. Typical values of $K_{p}$ are between 2 and 3, with storm time values approaching 7. Due to the non-uniform distribution of the contributing magnetometer stations, universal time variations are scaled out of the $\mathrm{K}_{\mathrm{p}}$ index.

The variation of the diurnal distribution of ion frictional heating with geomagnetic activity, the latter categorised according to the $\mathrm{K}_{\mathrm{p}}$ index, is illustrated in Fig. 8. Successive panels of this figure present the distribution of frictional heating for $\mathrm{K}_{\mathrm{p}} \leq 1, \mathrm{~K}_{\mathrm{p}}=2$, $\mathrm{K}_{\mathrm{p}}=3$ and $\mathrm{K}_{\mathrm{p}} \geq 4$. The total number of observations and the percentage occurrence of frictional heating at $312 \mathrm{~km}$ altitude for each range of $\mathrm{K}_{\mathrm{p}}$ are presented, respectively, as line plots and histograms. Figure 9 presents corresponding distributions of enhanced F-region ion velocity for these ranges of $\mathrm{K}_{\mathrm{p}}$.

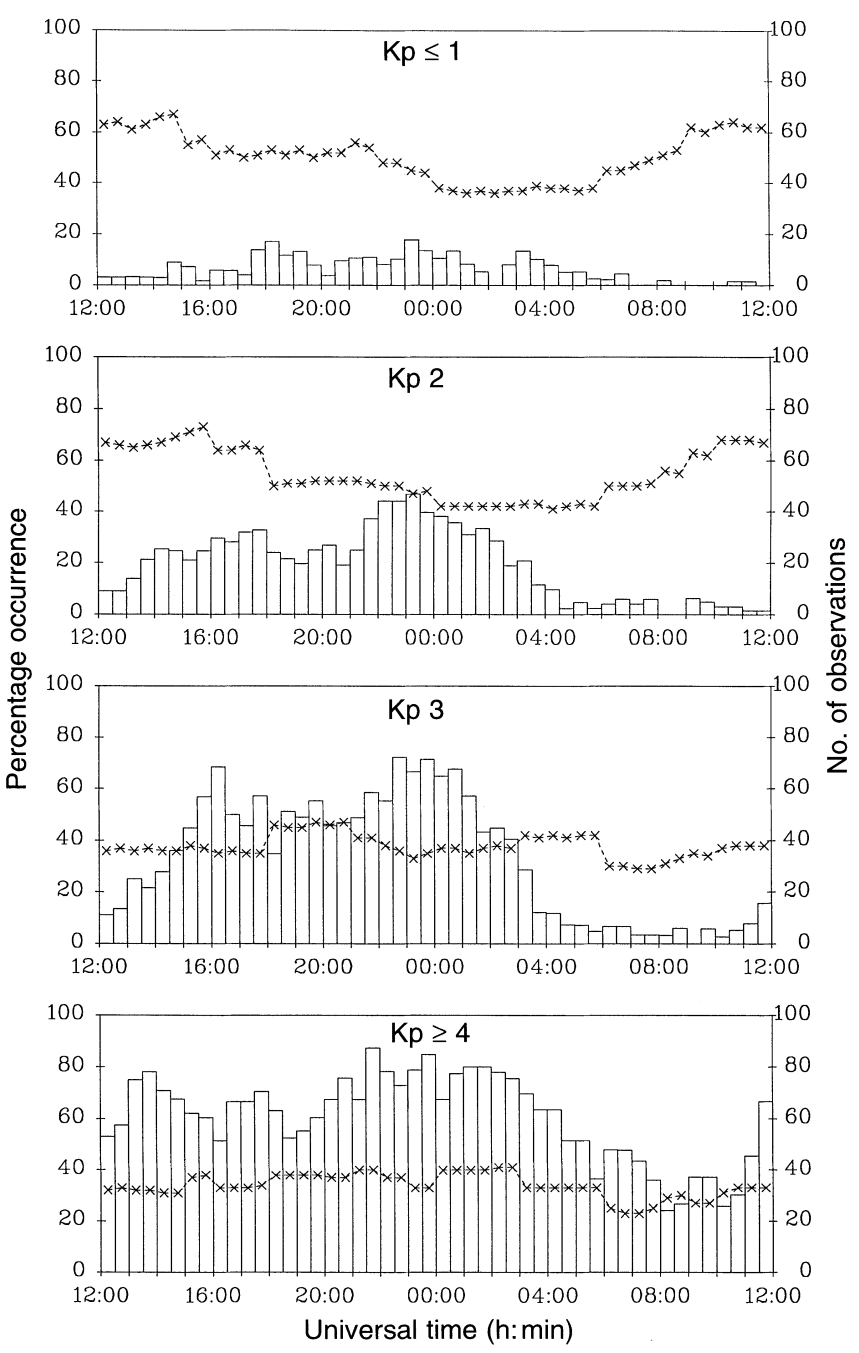

Fig. 8. Variation of the diurnal distribution of ion frictional heating with the level of geomagnetic activity, the latter of which is categorised according to $\mathrm{K}_{\mathrm{p}}$. Each panel is presented in the same form as Fig. 1
The percentage occurrence of ion frictional heating exhibits a dramatic increase with increasing geomagnetic activity over all universal times; at around 20:00 UT, for example, the probability of observing ion frictional heating increases from less than $10 \%$ for $\mathrm{K}_{\mathrm{p}} \leq 1$ to more than $70 \%$ for $K_{p} \geq 4$. Indeed for values of $K_{p}$ in excess of 4 , the occurrence of frictional heating observed around geomagnetic noon exceeds $30 \%$. Although the doublepeaked form of the diurnal distribution is pronounced during moderate geomagnetic activity, under both highly disturbed and undisturbed conditions this feature becomes less well defined. For quiet conditions, this is due to the low incidence of frictional heating throughout the day. In addition to an increase in the occurrence of ion frictional heating, both the enhancement in the fieldparallel ion temperature during identified intervals of ion frictional heating and the duration of these intervals tend to increase with increasing geomagnetic activity. The average enhancement in the parallel temperature for $K_{p} \leq 1$ is typically half of its value for $K_{p} \geq 4$.
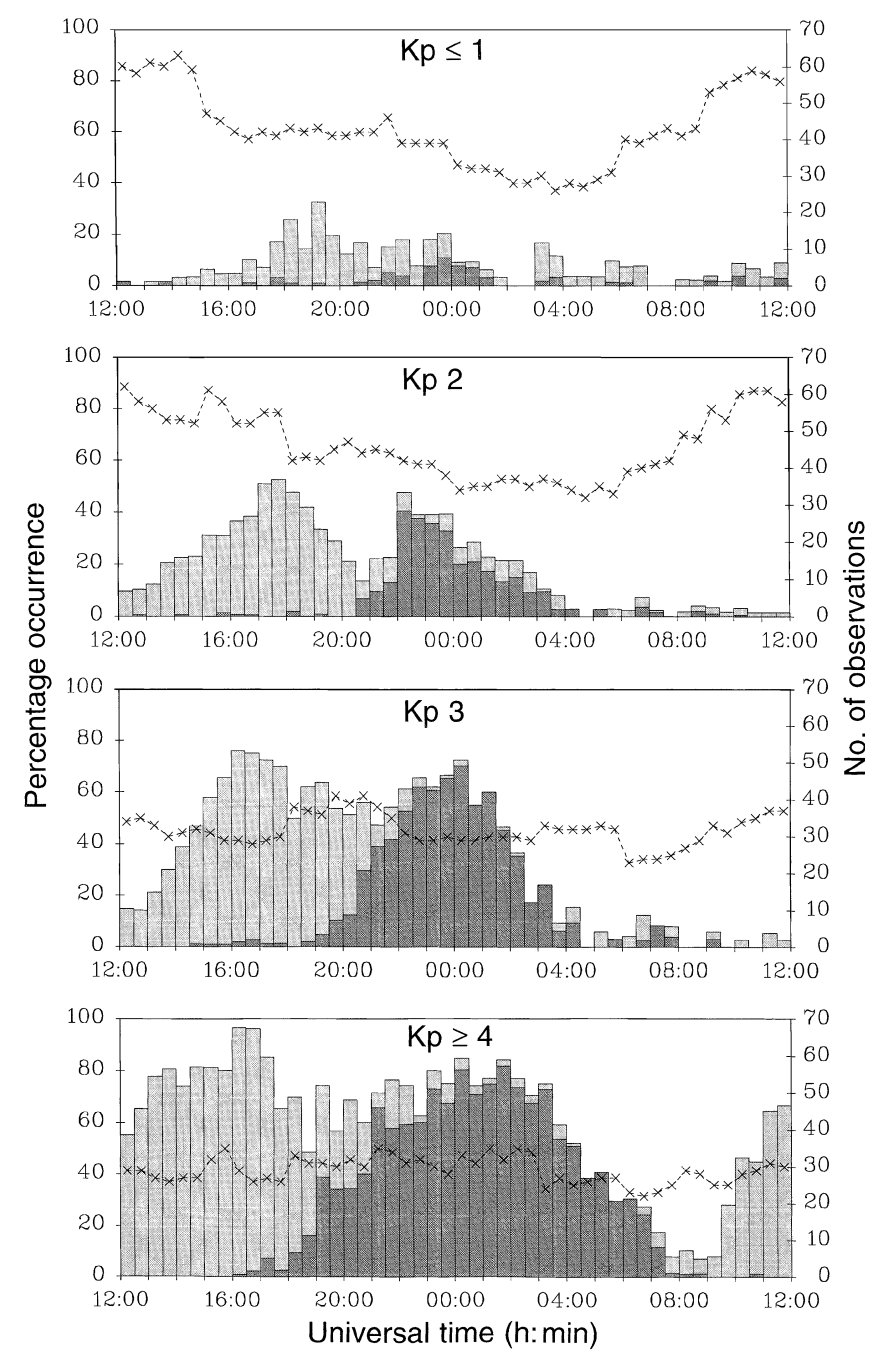

Fig. 9. Variation of the diurnal distribution of enhanced ion velocity with the level of geomagnetic activity, the latter of which is categorised according to $\mathrm{K}_{\mathrm{p}}$. Each panel is presented in the same form as Fig. 4 
The marked dependence of ion frictional heating on geomagnetic activity is clearly attributable to a corresponding dependence of the ion velocity (see Fig. 9). With increasing $\mathrm{K}_{\mathrm{p}}$ the occurrence of ion velocities in excess of $500 \mathrm{~m} \mathrm{~s}^{-1}$ increases significantly throughout the day. Indeed, the probability of observing high ion flows in any $30 \mathrm{~min}$ bin exceeds $80 \%$ over much of the day for $\mathrm{K}_{\mathrm{p}} \geq 4$, corresponding to highly disturbed conditions. This intensification of convection is a well-known characteristic with increasing geomagnetic activity and is a feature of all empirical models (e.g. Oliver et al., 1983; Holt et al., 1987) as well as being observed in studies of individual intervals (e.g. Alcaydé et al., 1986). This intensification is accompanied by the penetration of the convection pattern to lower magnetic latitudes. To some extent these results highlight the variation in the convection pattern with increasingly negative values of the $\mathrm{z}$ component of the interplanetary magnetic field, indeed reinforcing the results shown in the previous section.

Several authors have characterised the convection pattern as a function of $\mathrm{K}_{\mathrm{p}}$; for example Oliver et al. (1983) derived, as the basis of an empirical model, averaged drift patterns of the F-region plasma between 60 and $75^{\circ}$ invariant latitude as a function of $K_{p}$ from incoherent scatter observations by the Millstone Hill radar taken during 1978. The work of Senior et al. (1990) is perhaps more applicable to the present study. Senior et al. (1990) constructed average convection patterns derived from a database of about $900 \mathrm{~h}$ of EISCAT common programme 3 observations, taken between June, 1984 and November, 1987. As well as observing the intensification and extension of the convection pattern with increasing $\mathrm{K}_{\mathrm{p}}$, Senior et al. (1990) noted that the convection pattern rotated with increasing geomagnetic activity such that the average position of the nightside convection reversal moved to earlier local times. This had previously been suggested by the theoretical modelling of Fontaine and Blanc (1983) and was attributed by the authors to an increase, with increasing magnetic activity, of particle precipitation in the auroral zone. The results of Senior et al. (1990) indicated that, at the location of the radar, the centre of the convection reversal was displaced by some $2 \mathrm{~h}$; from 21:00 UT for $\mathrm{K}_{\mathrm{p}}$ less than 2 to 19:00 for $\mathrm{K}_{\mathrm{p}}$ in excess of 4 . This time shift is indeed evident in the present study (see Fig. 9) and is of comparable value. It must be remembered that the y component of the IMF can induce similar asymmetries in the convection pattern (e.g. de la Beaujardière et al., 1986; Burrage, 1988), although any $B_{\mathrm{y}}$ effects should be averaged out, to a large extent, by the inclusion of a prolonged data set, as $B_{\mathrm{y}}$ is as likely to be negative as positive. Senior et al. (1990) also noted that under geomagnetically active conditions, larger flows arose in the evening convection cell than are observed in the morning cell. At the location of EISCAT, Senior et al. (1990) found that for $\mathrm{K}_{\mathrm{p}}$ exceeding 4 , the maximum of the northward component of the electric field (equivalent to westward flow) in the dusk sector was some $25 \%$ higher than the equivalent southward component (eastward flow). This result appears to be reproduced in the present study, for
$K_{p} \geq 4$ the occurrence probability of enhanced westward flows is higher, although the relatively low number of observations under geomagnetically active conditions makes this assertion somewhat speculative.

\section{Summary and conclusions}

The results of a statistical study of F-region ion frictional heating have been presented. Around $4200 \mathrm{~h}$ of field-aligned observations from the EISCAT common programmes CP-1 and CP-2, taken between 1984 and 1995, comprised the data set on which the investigation was based. The diurnal distribution of ion frictional heating observed by EISCAT over this six year interval, at $312 \mathrm{~km}$ altitude in the F-region, was constructed; the identification criterion for intervals of frictional heating was based on high-latitude observations by one of the Atmospheric Explorer satellites. The distribution of frictional heating exhibits a double-peaked, although asymmetric, form centred around local magnetic midnight. This asymmetry results from the tendency for larger neutral winds to develop in the pre- as opposed to the post-midnight sector. Furthermore, the dependence of the diurnal distribution of ion frictional heating on the orientation of the interplanetary magnetic field and geomagnetic activity has been investigated. A marked increase in the occurrence of ion frictional heating is noted with increasing geomagnetic activity and, moreover, for intervals where the $\mathrm{z}$ component of the interplanetary magnetic field is southward; both interpreted with respect to corresponding dependencies of ionospheric convection. Furthermore, the y component of the IMF, which is known to introduce asymmetries into the ionospheric convection pattern, affects markedly the shape of the distribution of ion frictional heating. In a future paper, the authors intend to demonstrate and explain, with reference to the results presented here the dependence of ion frictional heating on season and solar activity.

Acknowledgements. Thanks are due to the director of EISCAT and his staff for operating the facility and supplying the data. EISCAT is an association of the national scientific agencies of Finland, France, Germany, Japan, Norway, Sweden and the United Kingdom. The authors would also like to thank M. Lockwood for constructive discussions concerning this work. J. A. Davies is supported by a grant from the Particle Physics and Astronomy Research Council.

Topical Editor D. Alcaydé thanks C. Peymoiat and J. Kelly for their help in evaluating this paper.

\section{References}

Alcaydé, D., and J. Fontanari, Neutral temperature and winds from EISCAT CP-3 observations, J. Atmos. Terr. Phys., 48, 931, 1986.

Alcaydé, D., P. Bauer and J. Fontanari, Dynamical coupling of the auroral F-region ionosphere and thermosphere: case studies, J. Atmos. Terr. Phys., 46, 625, 1984.

Alcaydé, D., G. Caudal and J. Fontanari, Convection electric fields and electrostatic potential over $61^{\circ}<\Lambda<72^{\circ}$ invariant latitude observed with the European incoherent scatter facility: 1 . Initial results, J. Geophys. Res., 91, 233, 1986. 
Axford, W. I., and C. O. Hines, A unifying theory of high-latitude geophysical phenomena and geomagnetic storms, Can. J. Phys., 39, 1433, 1961.

Baron, M. J., and R. H. Wand, F-region ion temperature enhancements resulting from Joule heating, J. Geophys. Res., 88, 4114, 1983.

Bartels, J., The standardised index, $\mathrm{K}_{\mathrm{s}}$ and the planetary index, $\mathrm{K}_{\mathrm{p}}$ Int. Union Geod. Geophys. IATME Bull., 97, 1949.

Burch, J. L., P. H. Reiff, J. D. Menietti, R. A. Heelis, W. B. Hanson, S. D. Shawhan, E. G. Shelley, M. Sugiura, D. R. Weimer, and J. D. Winningham, IMF By-dependent plasma flow and Birkeland currents in the dayside magnetosphere: 1. Dynamics Explorer observations, J. Geophys. Res., 90, 1577, 1985.

Burrage, M. D., Radar studies of high latitude convection flows. PhD Thesis, University of Leicester, UK, 1988.

Cowley, S. W. H., The causes of convection in the Earth's magnetosphere: a review of developments during the IMS, Rev. Geophys. Space Phys., 20, 531, 1982.

De la Beaujardiére, O., V. B. Wickwar, J. D. Kelly, and J. H. King, IMF- $B_{\mathrm{y}}$ effects on the high-latitude nightside convection, Geophys. Res. Lett., 12, 461, 1985.

De la Beaujardière, O., V. B. Wickwar, and J. H. King, Sondrestrom radar observations of the effect of the IMF $B_{\mathrm{y}}$ component on polar cap convection, in Solar wind-magnetosphere coupling, Terra Scientific Publishing Company, Tokyo, 595, 1986.

Fontaine, D., and M. Blanc, A theoretical approach to the morphology and dynamics of diffuse auroral zones, J. Geophys. Res., 88, 7171, 1983.

Foster, J. C., J. M. Holt, R. G. Musgrove, and D. S. Evans, Solar wind dependencies of high-latitude convection and precipitation, in Solar wind-magnetosphere coupling, Terra Scientific Publishing Company, Tokyo, 477, 1986.

Fox, N. J., M. Lockwood, S. W. H. Cowley, M. P. Freeman, E. Friis-Christensen, D. K. Milling, M. Pinnock, and G. D. Reeves, EISCAT observations of unusual flows in the morning sector associated with weak substorm activity. Ann. Geophysicae, 12, 541, 1994.

Friis-Christensen, E., Y. Kamide, A. D. Richmond, and S. Matsushita, Interplanetary magnetic field control of high-latitude electric fields and currents determined from Greenland magnetometer data, J. Geophys. Res., 90, 1325, 1985.

Holt, J. M., R. H. Wand, J. V. Evans, and W. L. Oliver, Empirical models for the plasma convection at high latitudes from Millstone Hill observations, J. Geophys. Res., 92, 203, 1987.

Lanchester, B. S., K. Kaila, and I. W. McCrea, Relationship between large horizontal electric fields and auroral arc elements, J. Geophys. Res., 101, 5075, 1996.

Lathuillère, C., and D. Hubert, Ion composition and ion temperature anisotropy in periods of high electric fields from incoherent scatter observations, Ann. Geophysicae, 7, 285, 1989.

Lester, M., O. De la Beaujardière, J. C. Foster, M. P. Freeman, H. Lühr, J. M. Ruohoniemi, and W. Swider, The response of the large scale ionospheric convection pattern to changes in the IMF and substorms: Results from the SUNDIAL 1987 campaign, Ann. Geophysicae 11, 556, 1993.

Lockwood, M., and S. W. H. Cowley, Ionospheric convection and the substorm cycle, in Substorms 1: Proceedings of the first international conference on substorms, European Space Agency Publications, Nordvijk, 99, 1992.

Lockwood, M., and T. J. Fuller-Rowell, The modelled occurrence of non-thermal plasma in the ionospheric F-region and the possible consequences for ion outflow into the magnetosphere, Geophys. Res. Lett., 14, 371, 1987a.

Lockwood, M., and T. J. Fuller-Rowell, Correction to The modelled occurrence of non-thermal plasma in the ionospheric F-region and the possible consequences for ion outflow into the magnetosphere, Geophys. Res. Lett., 14, 581, 1987b.

Lockwood, M., B. J. Bromage, R. B. Horne, J. -P. St-Maurice, D. M. Willis, and S. W. H. Cowley, Non-Maxwellian ion velocity distributions observed using EISCAT, Geophys. Res. Lett., 14, 111, 1987.

Lockwood, M., I. W. McCrea, G. H. Millward, R. J. Moffett, and H. Rishbeth., EISCAT observations of ion composition and temperature anisotropy in the high-latitude F-region, J. Atmos. Terr. Phys., 55, 895, 1993.

Løvhaug, U. P., and T. Flå, Ion temperature anisotropy in the auroral F-region as measured with EISCAT, J. Atmos. Terr. Phys., 48, 959, 1986.

McCrea, I. W., Radar observations of high-energy deposition and dissipation in the high-latitude ionosphere, $\mathrm{PhD}$ Thesis, University of Leicester, UK, 1989.

McCrea, I. W., M. Lester, T. R. Robinson, N. M. Wade, and T. B. Jones, On the identification and occurrence of ion frictional heating events in the high-latitude ionosphere, J. Atmos. Terr. Phys., 53, 587, 1991.

McCrea, I. W., G. O. L. Jones, and M. Lester, The BEAN experiment - an EISCAT study of ion temperature anisotropies, Ann. Geophysicae, 13, 177, 1995.

Moorcroft, D. R., and K. Schlegel, Evidence for non-Maxwellian ion velocity distributions in the F-region, J. Atmos. Terr. Phys., 50, $455,1988$.

Oliver, W. L., J. M. Holt, R. H. Wand, and J. V. Evans, Millstone hill incoherent scatter observations of auroral convection over $60^{\circ}<\Lambda<75^{\circ}: 3$. Average patterns verses $\mathrm{K}_{\mathrm{p}}$, J. Geophys. Res., 88, 5505, 1983.

Perraut, S., A. Brekke, M. Baron, and D. Hubert, EISCAT measurements of ion temperatures which indicate non-isotropic ion velocity distributions, J. Atmos. Terr. Phys., 46, 531, 1984.

Rees, M. H., and J. C. G. Walker, Ion and electron heating by auroral electric fields, Ann. Geophysicae, 24, 193, 1968.

Reiff, P. H., and J. L. Burch, $B_{\mathrm{y}}$-dependent plasma flow and Birkeland currents in the dayside magnetosphere: 2. A global model for northward and southward IMF, J. Geophys. Res., 90, 1595, 1985.

Rishbeth, H., Thermospheric winds and the F-region: a review, J. Atmos. Terr. Phys., 34, 1, 1972.

Rishbeth, H., and P. J. S. Williams, The EISCAT ionospheric radar: the system and its early results, $Q . J$. R. Astron Soc., 26, $478,1985$.

Rodger, A. S., S. W. H. Cowley, M. J. Brown, M. Pinnock, and D. A. Simmons, Dawn-dusk (y) component of the interplanetary magnetic field and the local time of the Harang continuity, Planet. Space Sci., 32, 1021, 1984.

Schunk, R. W., and J. J. Sojka, Ionospheric hot spot at highlatitudes, Geophys. Res. Lett., 9, 1045, 1982.

Schunk, R. W., W. J. Raitt, and P. M. Banks, Effect of electric fields on the daytime high-latitude E- and F-regions, J. Geophys. Res., 80, 3121, 1975.

Senior, C., D. Fontaine, G. Caudal, D. Alcaydé, and J. Fontanari, Convection electric fields and electrostatic potential over $61^{\circ}<$ $\Lambda<72^{\circ}$ invariant latitude observed with the European incoherent scatter facility: 2. Statistical results, Ann. Geophysicae, 8, 257, 1990.

St-Maurice, J. -P., and W. B. Hanson, Ion frictional heating at high-latitudes and its possible use for in situ determination of neutral thermospheric winds and temperatures, J. Geophys. Res., 87, 7580, 1982.

St-Maurice, J. -P., and R. W. Schunk, Ion velocity distributions in the high-latitude ionosphere, Rev. Geophys. Space Phys., 17, 99, 1979.

St-Maurice, J. -P., and D. G. Torr, Nonthermal rate coefficients in the ionosphere: the reactions of $\mathrm{O}^{+}$with $\mathrm{N}_{2}, \mathrm{O}_{2}$ and $\mathrm{NO}, J$. Geophys. Res., 83, 969, 1978.

St-Maurice, J. -P., W. B. Hanson, and J. C. G. Walker, Retarding potential analyzer measurement of the effect of ion-neutral collisions on the ion velocity distribution in the auroral ionosphere, J. Geophys. Res., 81, 5438, 1976. 
Todd, H., S. W. H. Cowley, M. Lockwood, D. M. Willis, and H. Lühr, Response time of the high-latitude dayside ionosphere to sudden changes in the north-south component of the IMF, Planet. Space Sci., 36, 1415, 1988.

Williams, P. J. S., T. S. Virdi, S. W. H. Cowley, and M. Lester, Short-lived bursts of plasma velocity in the auroral zone: 1 .
Observational evidence from radar measurements, J. Atmos. Terr. Phys., 52, 421, 1990.

Wygant, J. R., R. B. Torbert, and F. S. Mozer, Comparison of S3-2 polar cap potential drops with the interplanetary magnetic field and models of magnetopause reconnection, J. Geophys. Res., 88, 5727, 1983. 